\title{
Enhancing Wear Resistance of A356 Alloy by Adding CNFs Based on Ultrasonic Vibration Casting
}

\author{
Qing-Jie Wu ${ }^{1,2} \cdot$ Hong Yan ${ }^{1,2} \cdot$ Peng-Xiang Zhang ${ }^{1,2} \cdot$ Xue-Qin Zhu ${ }^{1,2} \cdot$ Qiao Nie $^{3}$
}

Received: 2 August 2017/Revised: 28 September 2017/Published online: 17 November 2017

(C) The Chinese Society for Metals and Springer-Verlag GmbH Germany, part of Springer Nature 2017

\begin{abstract}
A356-carbon nanofibers (CNFs) composites with different contents of CNFs were fabricated by ultrasonic vibration casting to investigate the effect of CNFs in the matrix on the mechanical properties and wear resistance. The worn surfaces were investigated using scanning electron microscopy (SEM). As the CNFs content was increased, strength, hardness and wear resistance were significantly enhanced and the coefficient of friction was extremely reduced. The nanocomposite containing $1.2 \mathrm{wt} \%$ of CNFs exhibited more than $109 \mathrm{HV}$ in hardness and less than 0.35 in the coefficient of friction. Compared with the as-cast matrix, the wear rate of the optimal composite was less than one-third of the matrix sample and the microhardness exhibited about $47 \%$ enhancement of the matrix. Meanwhile, steadier and lower friction coefficient was also achieved by the composite. CNFs were observed to be either partially or fully crushed forming a carbon film that covered the surface and acted as a solid lubricant, enhancing the wear behavior significantly.
\end{abstract}

KEY WORDS: A356 matrix composites; Carbon nanofibers; Wear testing

\section{Introduction}

Aluminum alloys are widely used in many engineering applications such as construction, automotive and aviation industries due to their adjustable elastic modulus and lightweight $[1,2]$. However, low hardness and consequently low wear resistance limit their application range. Recently, the addition of fibers or particulate reinforcements to aluminum alloys was widely reported for

Available online at http://link.springer.com/journal/40195

Hong Yan

hyan@ncu.edu.cn

1 School of Mechanical and Electrical Engineering, Nanchang University, Nanchang 330031, China

2 Key Laboratory of Light Alloy Preparation and Processing in Nanchang City, Nanchang 330031, China

3 Jiangxi Ling-Ge Non-ferrous Metal Processing Co., Ltd., Nanchang 330008, China imparting better wear resistance and strength [3, 4]. Shivamurthy et al. [5] found that the wear rate of A356 alloy was decreased by the addition of silicon carbide. AlQutub et al. [6] reported that the wear resistance of 6061 alloy with $10 \%$ alumina was increased by $45 \%$ on average compared to that of the matrix. Various other reinforcements have also been reported for improving tribological properties of aluminum-based alloys, such as short steel fibers [7], SiC fibers [8] and boron carbide [9, 10]. It can be noted from these studies that wear resistance increases due to high hardness and strength of the reinforcement phase.

Owing to their great physical-mechanical properties, carbon nanostructures are used as reinforcing component in metal-based composites in the last decade, such as nanotubes (CNTs) or fibers (CNFs). The superior mechanical and physical properties of carbon nanostructures have fascinated the research community [11]. Al-Qutub et al. [12] found that the applied load had a great influence on the friction and wear behavior of Al-CNT composites. When the load was beyond a critical value, the CNTs could have a negative impact on the wear resistance of the alloy. Zhou 
et al. [13] produced CNTs aluminum composites by the method of pressureless infiltration. They found that the wear rate and friction coefficient of the nanocomposite decreased steadily with increasing the volume fraction of CNTs (from 0 to 20 vol.\%). Kim et al. [14] reported similar results, and the authors found that the friction and wear characteristics of the composites prepared were related to the dispersion conditions. The dispersion of carbon nanostructures has been still challenging.

Ultrasound dispersion is an efficient method to obtain finely dispersed nanoparticles in aqueous solutions as cavitation is responsible for a high-energy input, resulting in nanoparticle de-agglomeration. The sparse structure of the melt is subjected to tensile stress and forms the microbubbles due to the high-intensity ultrasound. Then, these microbubbles involve the growth, pulsating and collapse in melt under cyclic high-intensity ultrasonic waves, leading to the occurrence of high pressure and temperatures $[15,16]$. Reportedly [17-20], the fiber clusters can be sufficiently broken up, and the interfaces are cleaned due to the implosive impact of high temperature and high pressure, permitting uniform dispersion in the matrix.

In the present study, mechanical properties and wear characteristics were investigated for A356 aluminum-based composites containing CNFs fabricated using ultrasonic cavitation-assisted casting. Meanwhile, the mentioned properties of the matrix have also been investigated under the same conditions in order to uncover the difference of wear mechanisms present in the A356-CNFs composites by providing an insight into the worn surfaces.

\section{Experiment}

The matrix material used for the preparation of the composite for this investigation was the standard A356 casting alloy, and its chemical composition is shown in Table 1. A typical micrograph of precipitator CNF used in this study is shown in Fig. 1 (purity $\geq 98 \%$, diameter of 50-200 nm, length of 3-12 $\mu \mathrm{m}$, low degree of aggregation). In order to remove the residual catalyst and amorphous carbon on the surface, these fibers were highly graphitized at $3000{ }^{\circ} \mathrm{C}$ prior to use.

CNFs were added into the alcohol and ultrasonically stirred for about 20-30 min for dispersion. After that, the

Table 1 Chemical composition of A356 alloy (wt\%)

\begin{tabular}{lllllll}
\hline Al & $\mathrm{Si}$ & $\mathrm{Mg}$ & $\mathrm{Fe}$ & $\mathrm{Zn}$ & $\mathrm{Mn}$ & $\mathrm{Cu}$ \\
\hline Bal. & 7.1 & 0.46 & 0.11 & 0.06 & 0.05 & 0.03 \\
\hline
\end{tabular}

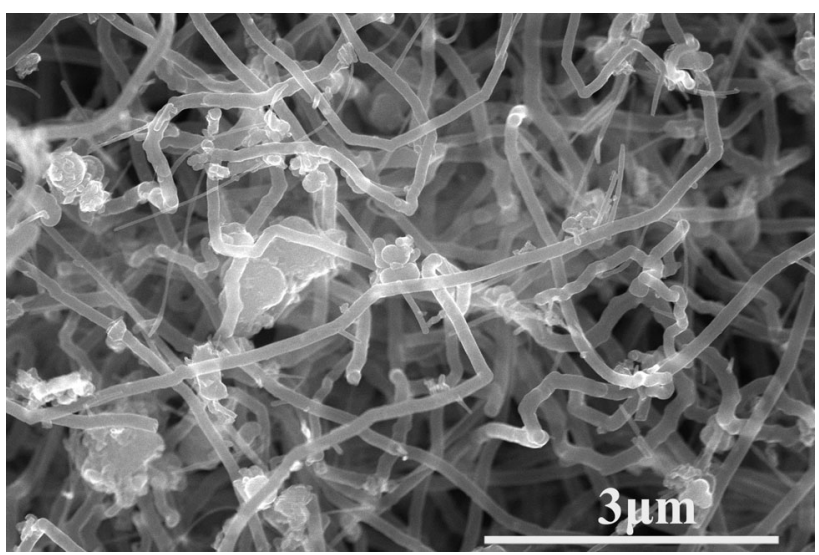

Fig. 1 SEM image of CNFs

appropriate $\mathrm{Al}$ powder was uniformly added and the sonication was continued for about $30 \mathrm{~min}$ again. Finally, this suspension was filtered and heated in a vacuum drying oven for $48 \mathrm{~h}$ to remove the alcohol. The resulting mixture was compacted at the pressure of $150 \mathrm{MPa}$ and extruded at $653 \mathrm{~K}\left(380{ }^{\circ} \mathrm{C}\right)$ at an extrusion ratio of $40: 1$ to produce $6 \%$ $\mathrm{CNF} / \mathrm{A} 356$ rod-shaped nanometer master alloy with a diameter of $6 \mathrm{~mm}$. The obtained nanomaster alloy was cut into small rods with length of 5-10 mm.

The A356 alloy ingot was melted at $750{ }^{\circ} \mathrm{C}$ in a corundum crucible by using a resistance furnace. Then, the Al-CNFs nanomaster alloy rods were pressed one by one into the A356 alloy melt. After the nanomaster alloy was completely melted, the melt was subjected to high-intensity ultrasonic or mechanical agitation treatment for $10 \mathrm{~min}$ in Ar atmosphere. The content of fibers in the CNFs/A356 nanocomposites fabricated was controlled by the added amount of the nanomaster alloy. The diameter of the corundum crucibles used in this experiment was 1.5 times of the ultrasonic probe diameter, and the aluminum alloy used for melting was less than $150 \mathrm{~g}$ each time. This was due to the attenuation of the ultrasound with the propagation distance in the melt, resulting in the dispersion effect being invalid at a longer distance from the probe. After the ultrasonic treatment, the melt was deslagged and poured into a preheated mold $\left(400{ }^{\circ} \mathrm{C}\right)$.

The microstructure of the CNFs/A356 nanocomposite sample was observed using an optical microscope (Nikon Eclipse MA200) and a scanning electron microscope (SEM, NOVA NanoSEM 450). The interfaces of CNF/ A356 composites were studied using a transmission electron microscope (TEM, JEM-2100). The hardness of the sample was measured by using a microscopic Vickers hardness tester (HVS 1000A). To reduce the error, the composite prepared was subjected to 10 indentations to obtain the average microhardness of each sample. Tensile tests were carried out using a universal testing machine to 
investigate the strengthening effect of different CNF contents.

The wear tests were conducted with a pin-on-steel disk tribometer as described in Ref. [21] at room temperature and under loads of 20,40 and $60 \mathrm{~N}$ at a rotational speed of $100 \mathrm{rpm}(0.188 \mathrm{~m} / \mathrm{s})$. ASTM1045 steel with 50HRC was used as disk. The pin samples of $\Phi 4.5 \mathrm{~mm} \times 12 \mathrm{~mm}$ were cut from the CNFs/A356 nanocomposite rods by wire electrical discharge machining. Before the wear test, the cylindrical pins and disk were polished, washed with ethanol solution and dried to obtain stable friction coefficient and wear rate in the tests. The wear tests were carried out to investigate the effects of the addition of the CNFs and the applied loads on the wear behavior of the A356 matrix and A356-CNFs (with different contents). To obtain a precise average value, the wear rates of five replicate samples were measured at each condition. The weight of the samples was measured before and after the wear test using an FA2204B electronic balance with an accuracy of $0.1 \mathrm{mg}$. The wear track morphology and the worn surfaces were investigated by SEM (NOVA NanoSEM 450) also.

\section{Results and Discussion}

Stir casting, as an alternative and relatively simple route, can be used to produce metal matrix composites. However, the application of this method for producing the composites reinforced with nanoparticles is much hampered [15]. Articles on composites reinforced with CNFs are few. Therefore, the method of mechanical agitation was tried to fabricate the composites with CNFs in this work. Unfortunately, the optimal composite, as shown in Fig. 2a, contains CNFs agglomerated. It can also be noted that the eutectic silicon ( $\mathrm{Si}$ ) was distributed along the grain boundaries of the $\alpha$-Al phases and a large amount of CNFs aggregation distributed along the grain boundaries unevenly in the nanocomposites. Figure $2 b$ shows the microstructures of nanocomposites prepared by high-intensity ultrasonic treatment at power of $2.1 \mathrm{KW}$. In accordance with the figure, the aggregations of CNFs were scattered to finer dark gray phases and distributed evenly around the Si phases after the processing of casting under ultrasonic vibration.

Figure 3a exhibits the SEM micrograph of the chemically etched cross section of the composite. It was not possible to observe clearly CNFs in the composite without deep etching. As shown in Fig. 3a, the rod-shaped CNFs were distributed near the grain boundaries or kept at semiburied state in grains. Figure $3 b$ shows a TEM image of the composite with 0.9 wt $\%$ of CNFs. The multiwall structure of CNFs is clearly visible in the TEM image. The well- straight shape was retained in the composite, which indicated that CNFs were not damaged during the fabrication process. Meanwhile, the surface of CNF does not exhibit light spots as can be seen from Fig. 3b, which can be concluded that interfacial bonding with the matrix was achieved.

Tensile properties and microhardness of matrix and composites fabricated with different contents of CNFs are shown in Table 2. The tensile strength and elongation of the matrix were $261 \mathrm{MPa}$ and $6 \%$, respectively. It is noticeable that the microhardness, ultimate tensile strength (UTS) and yield strength (YS) all exhibited increasing trends with the increase in CNFs. The YS and UTS of the nanocomposite at CNF content of $0.9 \mathrm{wt} \%$ were 202 and 261.2 MPa, correspondingly. The microhardness of the composites was $109 \mathrm{HV}$ at CNFs content of $1.2 \mathrm{wt} \%$. These can be attributed to the load transfer from the matrix to the nanofibers and the thermal expansion mismatch strengthening $[18,19]$. And the UTS of composite strengthened by load transfer from the matrix to short fibers was established by the Kelly-Tyson formula [20], given as

$\sigma_{\mathrm{c}}=\sigma_{\mathrm{f}} V_{\mathrm{f}}\left(1-\frac{l}{2 l_{\mathrm{c}}}\right)+\sigma_{\mathrm{m}}\left(1-V_{\mathrm{f}}\right)$,

where $V_{\mathrm{f}}$ is the volume fraction, $\sigma_{\mathrm{f}}$ is the strength of the fiber, and $\sigma_{\mathrm{m}}$ is the strength of the matrix. In this study, $\sigma_{\mathrm{f}}$ is assumed to be $13 \mathrm{GPa}$ [22]. According to the volumemass conversion, a volume content of $0.5-1.9 \%$ can be obtained. $\sigma_{\mathrm{m}}$ is equal to $214 \mathrm{MPa}$, and $l_{\mathrm{c}}$ is the length of the fiber when the composite is broken. The theoretical values are calculated to be $245.43-334 \mathrm{MPa}$. And these values are higher than the ones obtained in the tensile test. This result was due to the inconsistent orientation of the CNFs in the nanocomposites and resulted in only part of the CNFs subjected to the tensile loads.

On the other hand, the prismatic punching of dislocation occurred because of the considerable mismatch in the coefficient of thermal expansion between the CNFs and the aluminum matrix. It can be seen from Fig. 4 that there are lots of dislocations in the fabricated composites. This phenomenon would result in the enhancement of the material properties in turn.Dislocation density $\rho$ is given by

$\rho=10 A \varepsilon /(b t(1-A))$,

where $t$ is the diameter of the reinforcement (CNFs), $b$ is the Burgers vector, $\varepsilon$ is the thermal strain, and $A$ is the volume fraction of reinforcement (CNFs).The theoretical enhancement of the composites is

$\Delta \sigma=\alpha \mu \rho^{(1 / 2)} b$,

where $\alpha=1.25, \mu$ is the stiffness modulus of rigidity of the matrix (Al), and $b$ is the Burgers vector. 

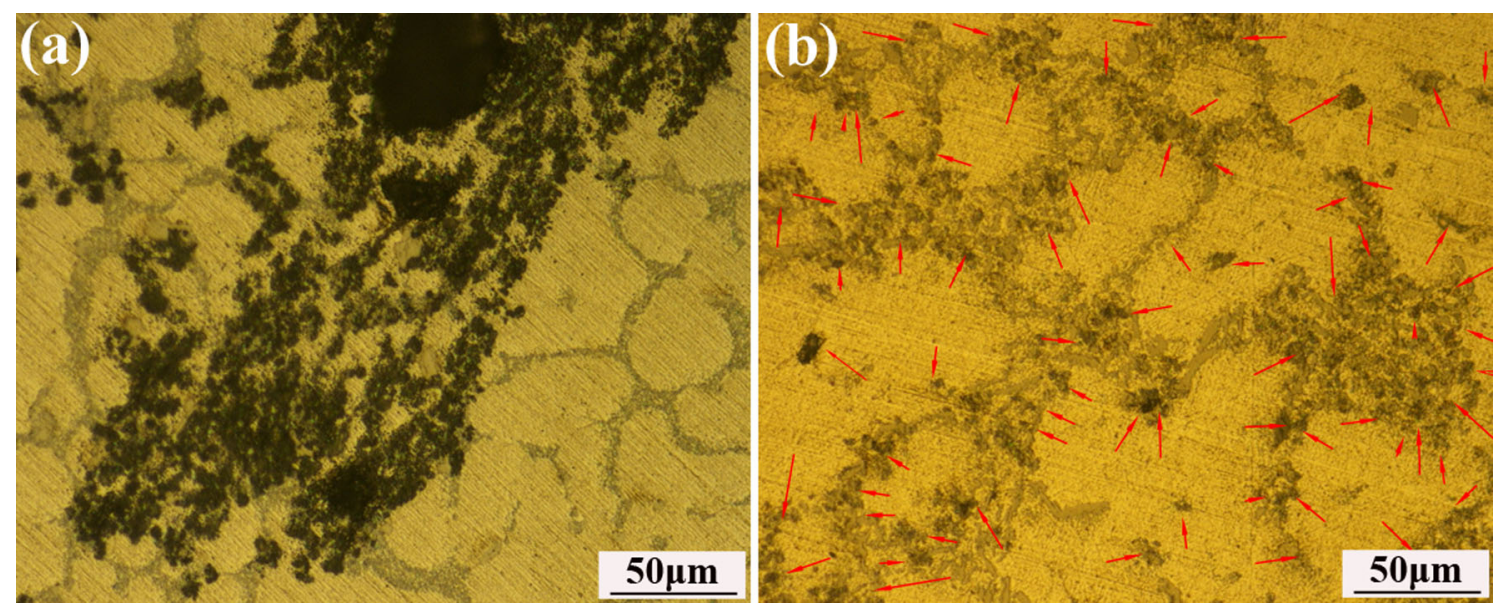

Fig. 2 Microstructures of the $0.9 \mathrm{wt} \% \mathrm{CNFs} / \mathrm{A} 356$ nanocomposites fabricated by a mechanical stirring, b high-intensity ultrasonic treatments
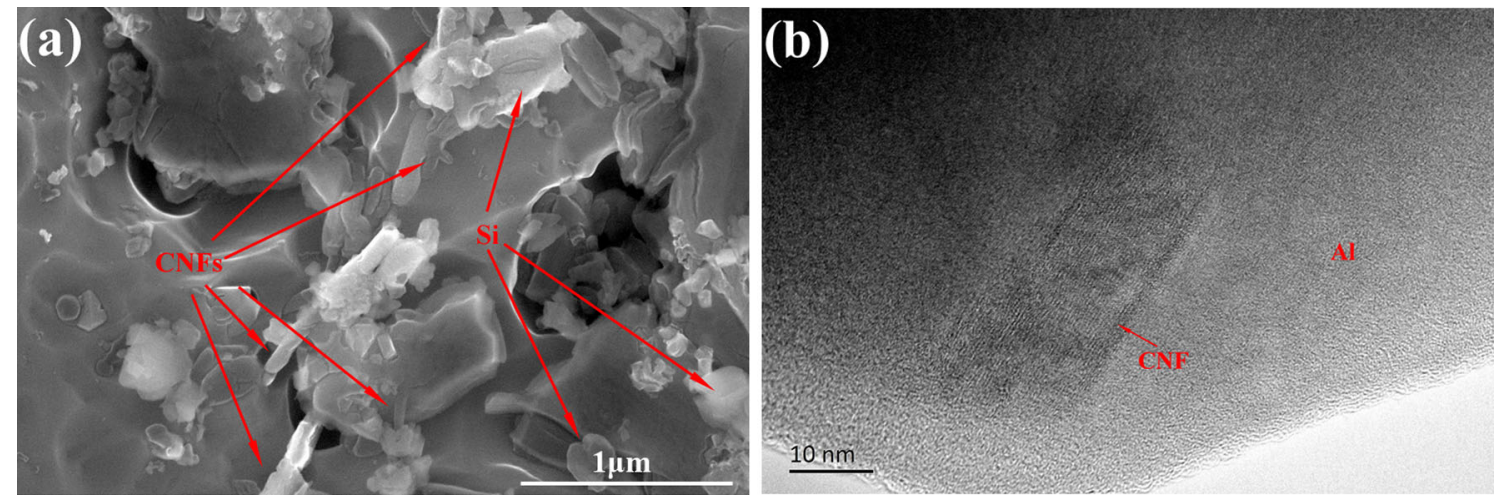

Fig. 3 SEM a, TEM b images of CNFs in the composites

Table 2 Tensile properties and Vickers hardness of CNFs/A356 nanocomposites prepared with different CNFs contents

\begin{tabular}{llccc}
\hline Materials & YS (MPa) & UTS (MPa) & Elongation (\%) & Vickers hardness (HV) \\
\hline A356 & $145 \pm 4$ & $214 \pm 4.42$ & $6 \pm 0.42$ & $74 \pm 3.9$ \\
A356 + 0.3 wt\% & $151 \pm 3.62$ & $217 \pm 5.21$ & $5.8 \pm 0.49$ & $82 \pm 4.3$ \\
A356 + 0.6 wt\% & $176 \pm 3.86$ & $242 \pm 4.38$ & $5.52 \pm 0.43$ & $90 \pm 4.23$ \\
A356 + 0.9 wt\% & $202 \pm 4.4$ & $261.2 \pm 6.26$ & $5.1 \pm 0.36$ & $106 \pm 4.1$ \\
A356 + 1.2 wt\% & $200 \pm 4.93$ & $254.1 \pm 5.74$ & $3.9 \pm 0.25$ & $109 \pm 3.75$ \\
\hline
\end{tabular}

It can be noted from formula (3) that the increment of intensity is proportional to the number of dislocations. Formula (1) shows that the dislocation density depends on the value of the volume fraction and the diameter of the reinforcement when the thermal strain of reinforcement is a constant. One of the advantages of CNFs is their small diameter, which, according to formula (2), causes the emergence of many dislocations and thus leads to the improvement in the mechanical properties of the nanocomposites.

Figure 5 shows the coefficients of friction of the matrix and the composite materials at an applied load of $40 \mathrm{~N}$.
Among them, Fig. 5a exhibits the average wear rates of the test samples. Figure $5 \mathrm{~b}-\mathrm{f}$ shows the typical friction coefficient variations with sliding time. Obviously, the friction coefficient and the wear rates exhibited decreasing trends with increasing the mass fraction of CNFs content. The wear rate of composite with $0.3 \mathrm{wt} \% \mathrm{CNFs}$ was slightly lower than the one of the A356 matrices. However, further increasing the content of CNFs, the wear rate and the average coefficient of friction were keeping decreased. Especially when the addition of CNFs reached $0.9 \mathrm{wt} \%$, the wear rate and the coefficient of friction of the composite reduced to 15.7 and 0.394 , respectively. Furthermore, the 


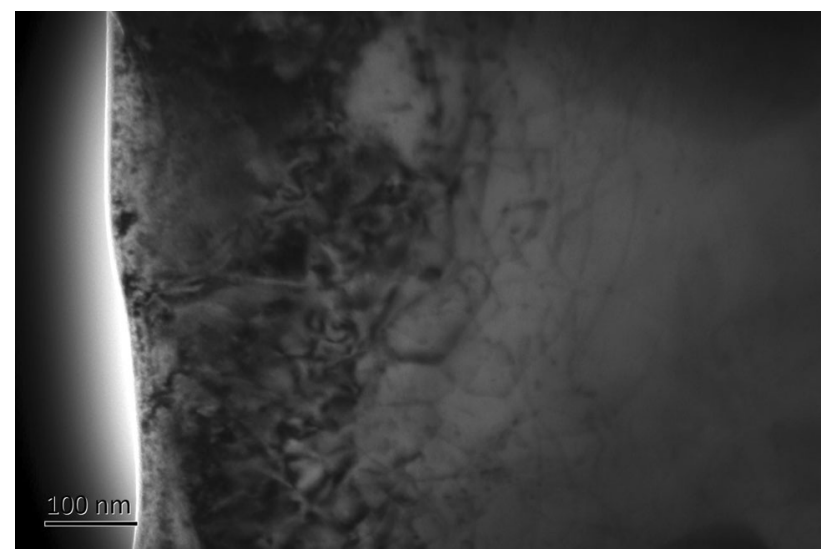

Fig. 4 TEM image of dislocations found in the nanocomposites composite containing $1.2 \mathrm{wt} \%$ of CNFs showed low coefficient of friction of 0.35 , which was much lower than the matrix. Meanwhile, it was also noted that the fluctuation in the coefficient of friction was less at higher CNFs content. The calculation result showed that the fluctuation value of CNFs nanocomposites decreased from 0.0615 to 0.0323

In general, the wear rate of alloy is inversely proportional to its hardness $[23,24]$. With increasing the CNFs mass fraction, microhardness of composites is additionally enhanced. And the increase in hardness can limit the shape deformation. So, the corresponding values of the wear rates decrease.

Table 3 shows a comparison of dry sliding wear of composites reinforced with $\mathrm{CNFs}, \mathrm{Al}_{2} \mathrm{O}_{3}$ and $\mathrm{SiC}$. Rohatgi
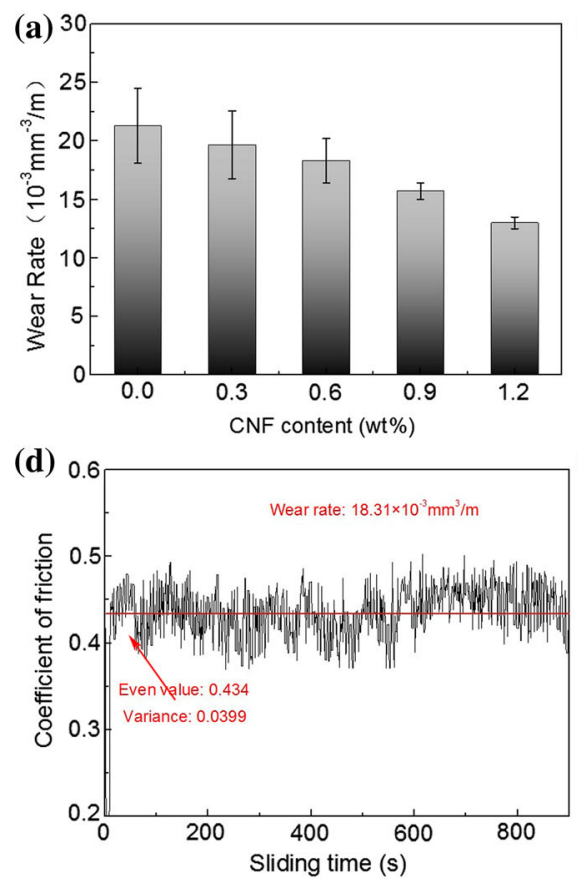

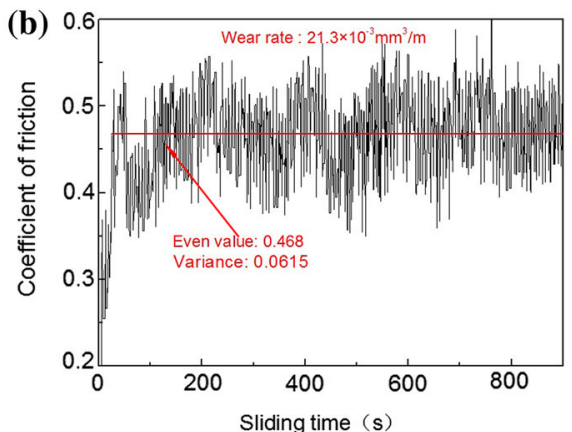

(e)

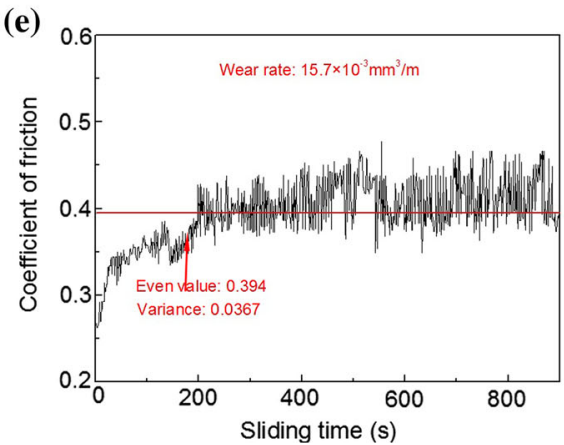

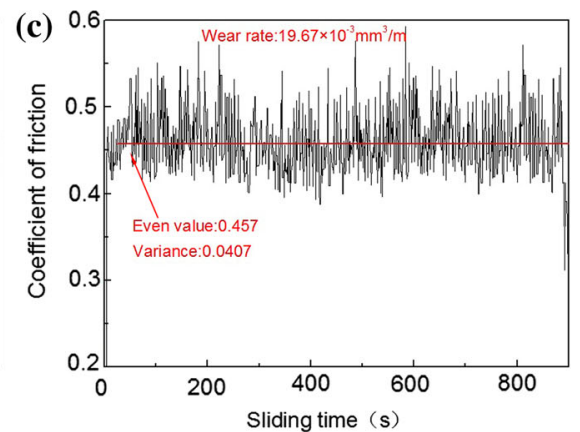

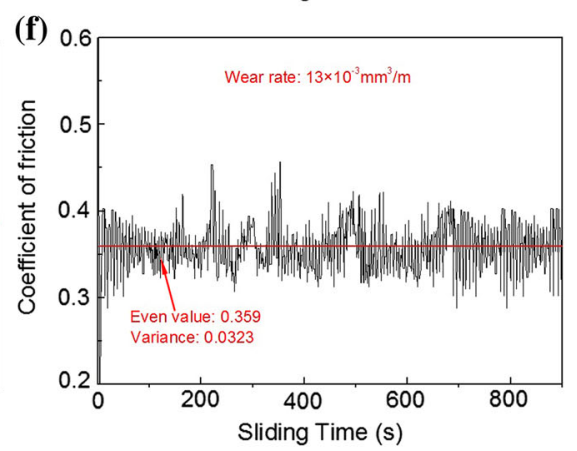

Fig. 5 Wear rate versus CNF wt $\%$ a. Variations of coefficient of friction as a function of CNFs content: b A356 matrix, c 0.3 wt $\%$ CNFs/A356, d 0.6 wt $\%$ CNFs/A356, e 0.9 wt $\%$ CNFs/A356, f 1.2 wt $\%$ CNFs/A356

Table 3 Comparison of the dry sliding wear rates of A356 composites reinforced with different reinforcements

\begin{tabular}{|c|c|c|c|c|c|}
\hline Investigators & Test configuration & Test conditions & Materials & $\begin{array}{l}\text { Wear rate } \\
\left(10^{-3} \mathrm{~mm}^{3} / \mathrm{m}\right)\end{array}$ & Optimization ratio $(\%)$ \\
\hline Rohatgi et al. [25] & Pin on disk & $\begin{array}{l}v=1.0 \mathrm{~m} / \mathrm{s} \\
L=2.97 \mathrm{~N} \\
t=300 \mathrm{~s}\end{array}$ & $\begin{array}{l}\text { A } 356 \\
\text { A356 + } 5 \text { vol. } \% \text { fly ash particles }\end{array}$ & $\begin{array}{l}70 \\
51.3\end{array}$ & 26 \\
\hline Cree and Pugh [26] & Ball on disk & $\begin{array}{l}L=20 \mathrm{~N} \\
v=33 \mathrm{~mm} / \mathrm{s}\end{array}$ & $\begin{array}{l}\text { A } 356 \\
\text { A356 }+12 \text { vol. } \% \mathrm{SiC} \text { foam }\end{array}$ & $\begin{array}{l}28 \\
25\end{array}$ & 10.7 \\
\hline Present authors & Pin on disk & $\begin{array}{l}v=0.188 \mathrm{~m} / \mathrm{s} \\
L=40 \mathrm{~N} \\
t=900 \mathrm{~s}\end{array}$ & $\begin{array}{l}\mathrm{A} 356 \\
\mathrm{~A} 356+1.2 \mathrm{wt} \% \mathrm{CNFs}\end{array}$ & $\begin{array}{l}21.3 \\
13\end{array}$ & 39 \\
\hline
\end{tabular}



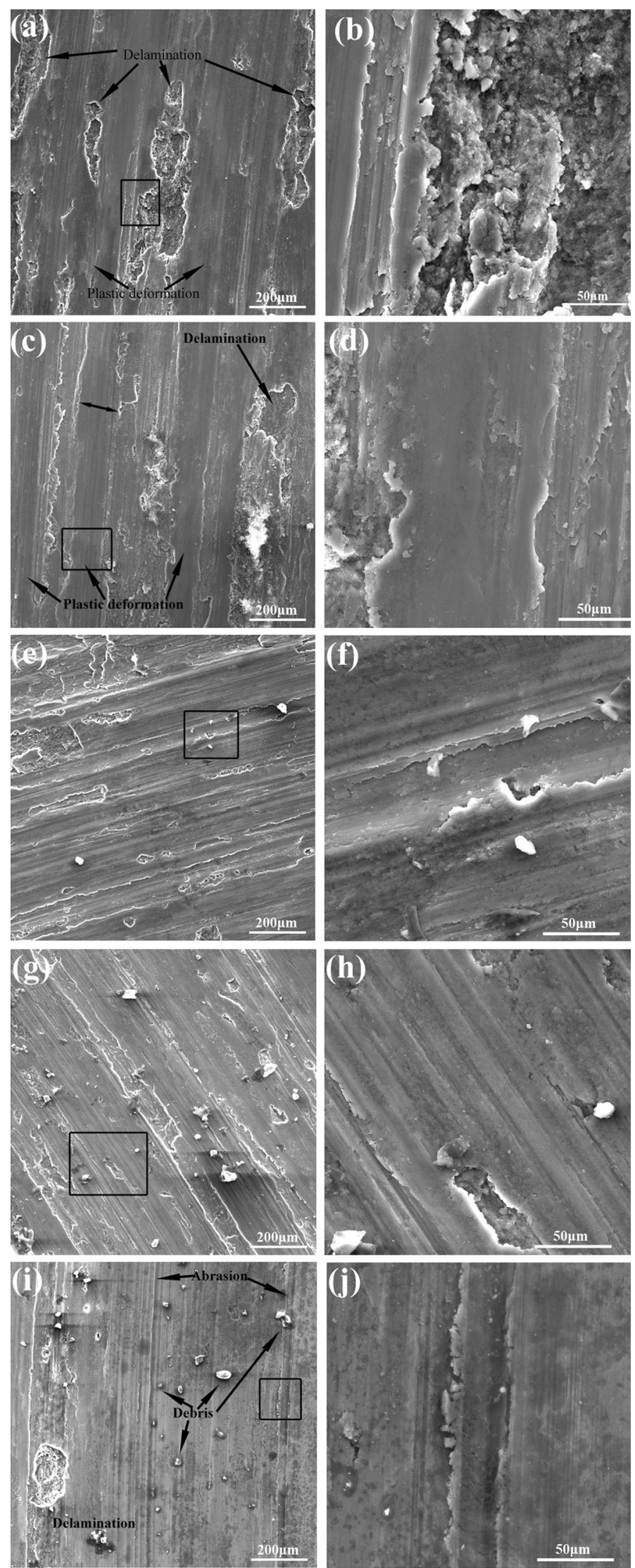
4Fig. 6 SEM images of the friction surfaces of nanocomposites after friction tests: a, b A356 matrix, c, d 0.3 wt\% CNFs/A356, e, f 0.6 wt\% CNFs/A356, g, h 0.9 wt\% CNFs/A356, i, j 1.2 wt\% CNFs/A356

et al. [25] fabricated 5 vol.\% fly ash/A356 composite by stir casting technology. According to their report, the sliding wear rates of composite and A356 matrix were $51.3 \times 10^{-3}$ and $70 \times 10^{-3} \mathrm{~mm}^{3} / \mathrm{m}$, respectively. The optimization ratio of the wear rate was $26 \%$. Cree et al. [26] produced the corresponding composites by adding $12 \mathrm{vol} . \% \mathrm{SiC}$ foam. The sliding wear rates of composite and the matrix were $25 \times 10^{-3}$ and $28 \times 10^{-3} \mathrm{~mm}^{3} / \mathrm{m}$, respectively. The optimization ratio of the wear rate was about $10.7 \%$. In contrast, the composites reinforced with CNFs achieved a much lower relative wear. The sliding wear rate of composite reinforced with $1.2 \mathrm{wt} \% \mathrm{CNFs}$ is $13 \times 10^{-3} \mathrm{~mm}^{3} / \mathrm{m}$. The optimization ratio of the wear rate is $39 \%$.

Figure 6 shows SEM images of worn surfaces as a function of varying CNFs content at $40-\mathrm{N}$ load. It could be noticed that lots of smooth stripes appeared on the worn surfaces of matrix and $0.3 \mathrm{wt} \% \mathrm{CNFs} / \mathrm{A} 356$ composite. This illustrated the serious plastic deformation of the samples produced in the wear processing. However, the surface of the materials ( $0.6 \mathrm{wt} \% \mathrm{CNFs})$ revealed lots of deep grooves as can be seen in the SEM. This phenomenon indicated that the wear mechanism of the composites was dominated by abrasive wear. It can also be noticed that the worn direction

lubricating layer (carbon debris and CNFs)

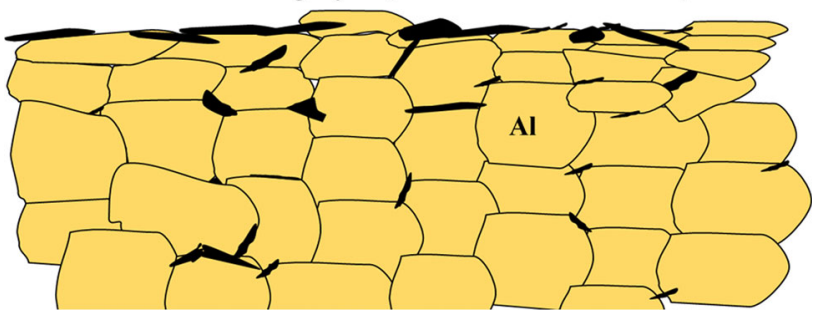

Fig. 8 Schematic presentation of the wear mechanism of A356CNFs

width of the abrasion scars decreased with the increase in the CNFs. Especially when the amount of the CNFs is 0.9 or $1.2 \mathrm{wt} \%$, the surfaces of the samples exhibited the finer scars and lots of debris as can be seen from the SEM images. Although some delamination pits were also present, the surface of the wear tracks was featureless and rather smooth along the sliding direction. The wear performance of the alloy was improved obviously. This phenomenon was indicated by the significant decline of friction coefficient and variance value as shown in Fig. 5.

To research the wear mechanism of the alloy, the chemical composition of the sample in Fig. 6i was examined by SEM and EDS (Fig. 7). The results showed that

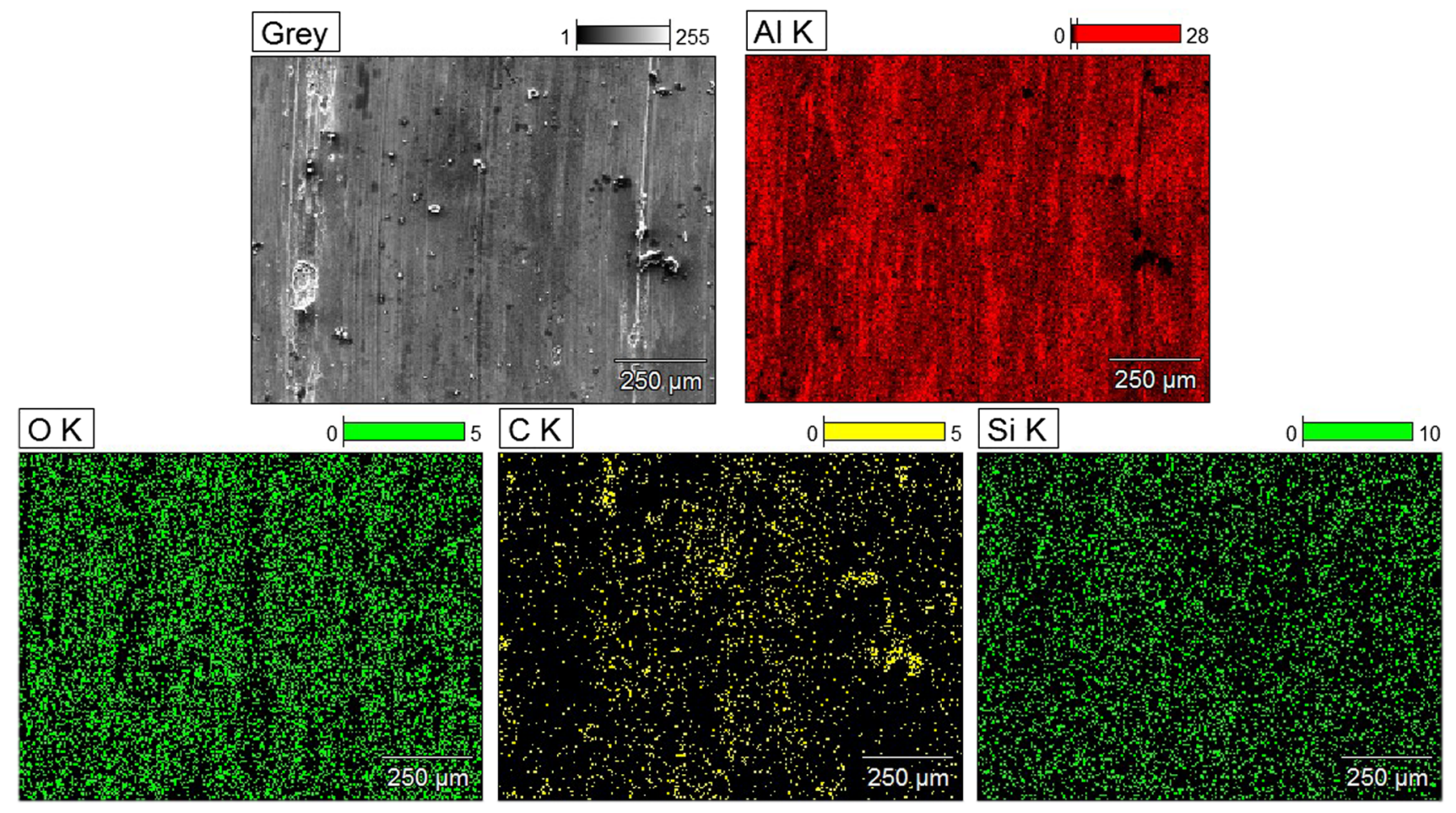

Fig. 7 X-ray elemental maps of the worn surface for $1.2 \mathrm{wt} \% \mathrm{CNFs} / \mathrm{A} 356$ nanocomposite after friction test 

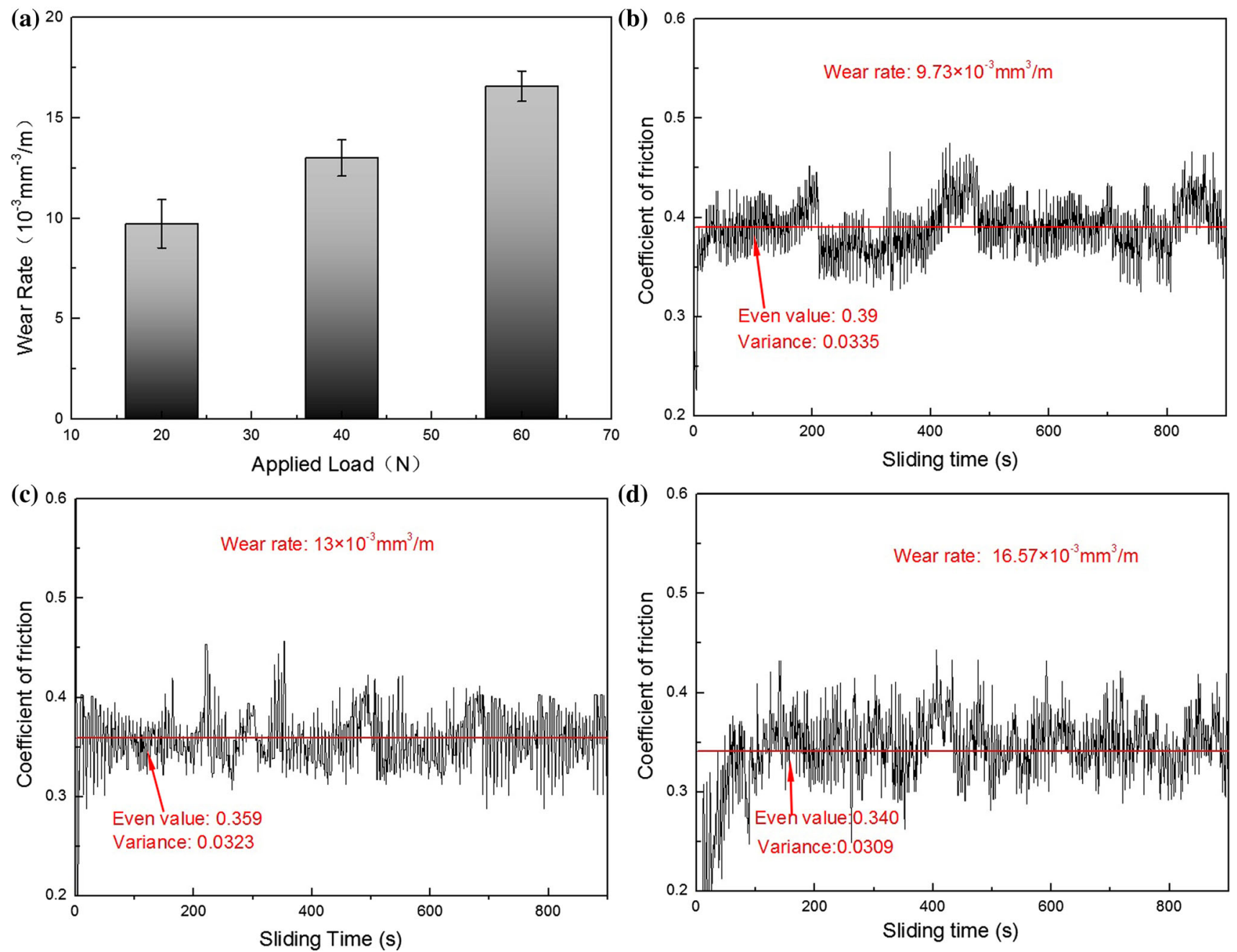

Fig. 9 Wear rate of the A356-1.2 wt\% CNF composite under different applied loads a; friction coefficient for A356/1.2 wt\% CNFs at b $20 \mathrm{~N}$, c $40 \mathrm{~N}, \mathbf{d} 60 \mathrm{~N}$
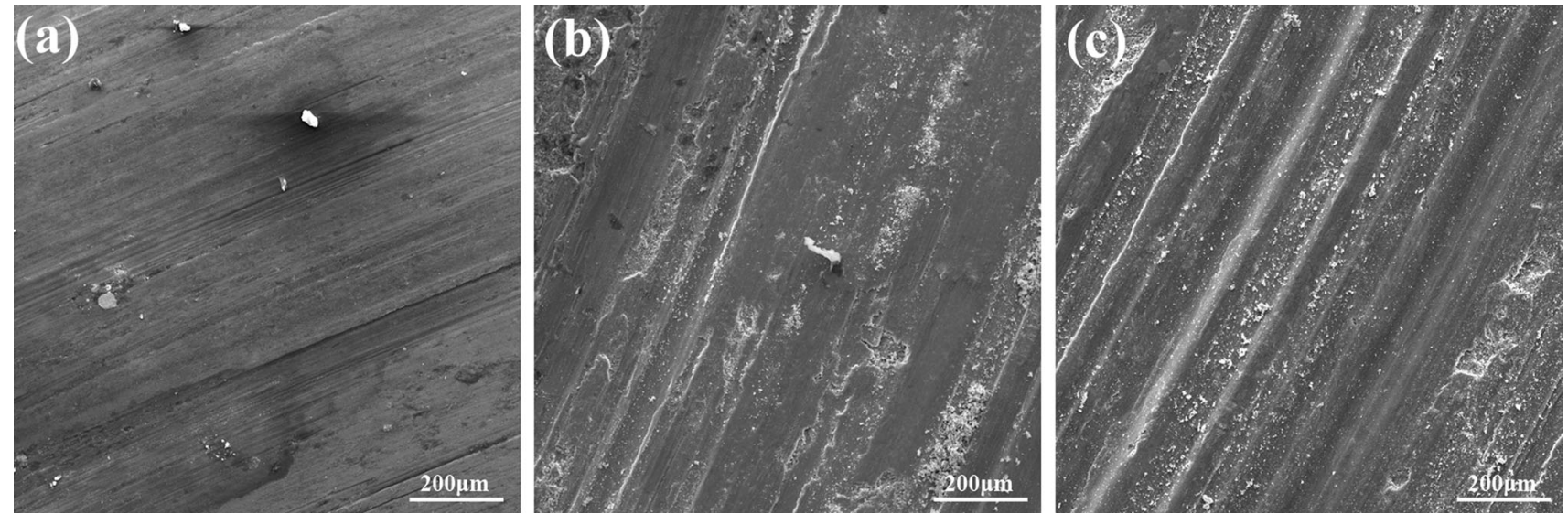

Fig. 10 SEM micrographs of the worn surfaces of A356/1.2 wt \% CNFs at a load of a $20 \mathrm{~N}, \mathbf{b} 40 \mathrm{~N}$, c $60 \mathrm{~N}$

there were a lot of carbon atoms existed on the surface of the sample in addition to aluminum and oxygen elements. This indicated the formation of the carbon film on the surface of the sample during the process (Fig. 8). Similar phenomenon was observed by Choi et al. [27] in the wear tests of Al-CNTs. The author attributed the reduction in 

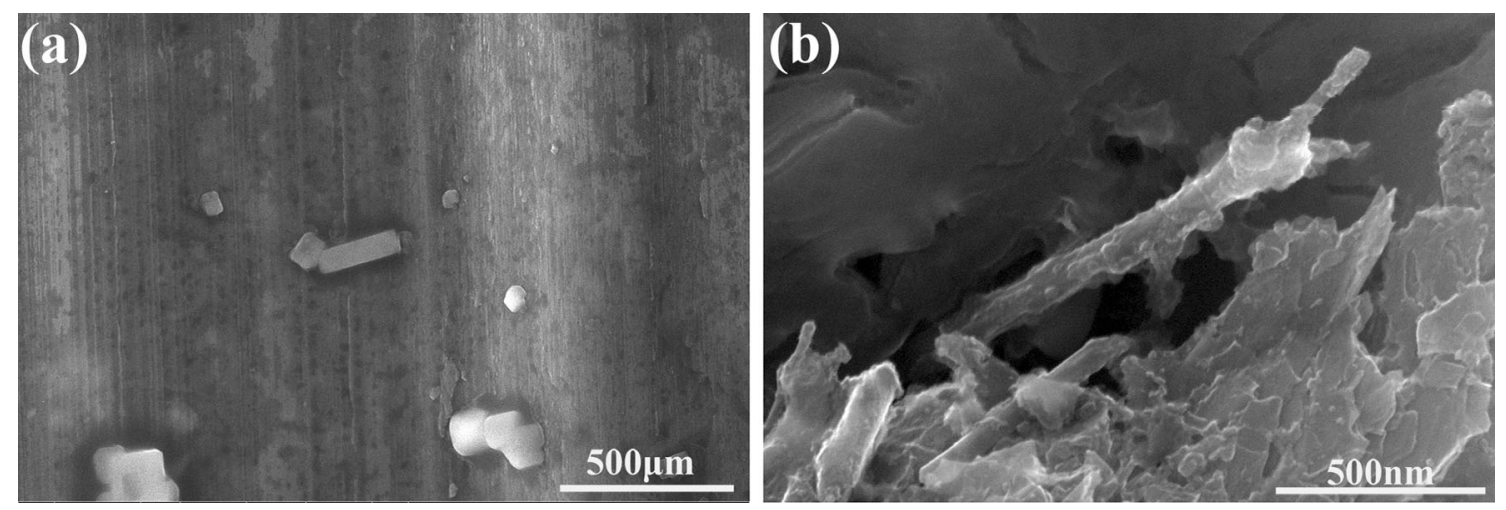

Fig. 11 CNFs on the worn surfaces of A356/1.2 wt\% CNFs composites after friction tests: a $60 \mathrm{~N}, \mathbf{b} 40 \mathrm{~N}$

the friction coefficient to the self-lubricating effects of the carbon film. Kim et al. [28] believed that the film of carbon can cover the wear surface and act as a solid lubricant that decreases the coefficient of friction. Therefore, the formation was believed to result in a smoother friction trace as can be seen from Fig. 6j. Furthermore, the fraction of the $\mathrm{CNFs}$ on the sample surface increased with increasing CNFs content, and the direct contact areas between the alloy and the disk decreased, thus contributing to the reduction in the friction coefficient. On the other hand, it can be seen from Table 2 that the microhardness of the alloy was improved with the increase in CNFs content, which limited the plastic deformation of the samples directly. Meanwhile, the excellent thermal conductivity of the CNFs improved the thermal conductivity of the composite material, which helped to release the heat generation and maintained the strength and hardness of the composite at high temperatures [29], resulted in a more stable value of the coefficient of dynamic friction.

The wear rates of the $1.2 \mathrm{wt} \% \mathrm{CNFs} / \mathrm{A} 356$ nanocomposites under different applied loads are shown in Fig. 9. Among them, Fig. 9a shows the average wear rates of the nanocomposites. It is noted that the wear rate increases with the increase in the applied load. Figure $9 \mathrm{~b}-\mathrm{d}$ presents the dynamic coefficient of friction for the samples. The average coefficient of friction observably decreased with the increase in the applied loads. The fluctuation of friction coefficient was less at higher loads. In general, under the lower load, the CNFs are wearing off gradually. The real contact area consists of very small contacts at asperity tips. The formation of carbon film is limited. However, the improvement in the plowing force of the sample [27] increases the probability of pulling or crushing CNFs from the matrix and thus increases the efficiency of lubrication. Moreover, with increasing applied load, greater frictional heating leads the pin surfaces to grow progressively weaker and therefore allows easier sliding at the interface [20] due to generating higher plastic deformation.
Figure 10 shows SEM micrographs of the worn surface of $1.2 \mathrm{wt} \% \mathrm{CNFs} / \mathrm{A} 356$ samples tested at different applied loads. It can be noticed from Fig. 10 that the width of the abrasion scars increased with the increase in the applied load. Slight scratches can be noticed in monolithic alloy when the applied load was $20 \mathrm{~N}$. When the applied load was improved to $40 \mathrm{~N}$, the surface of the tested sample showed some delamination and the width of the abrasion scars slightly enlarged. The surface of the wear tracks was rather smooth along the sliding direction as we mentioned before. However, when the applied load was improved to $60 \mathrm{~N}$, lots of smooth and wider scars appear on the surface as can be seen in the SEM. This phenomenon was due to the increasing of the load increased the deformation of the sample tested and the damages of surface caused by debris.

Figure 11a presents a SEM image of the worn surface of the sample tested under 60-N applied load. The SEM observation reveals some damaged CNFs resting freely on the worn surface. This observation supports early argument: The high applied load increases the probability of crushing CNFs from the matrix. Such exposed CNFs attached to the matrix can increase wear resistance effectively due to the direct contact with the friction surface, reducing the surface fraction of the worn surface [26]. Figure 11b shows the SEM observation of CNFs on the position of delamination pit after worn tests under $40-\mathrm{N}$ applied load. In fact, there were no typical CNFs observed on worn surface of the sample, and only a small amount of small diameter CNFs were found at that location. It was possible that the CNFs nanostructures were worn into debris under this load. Meanwhile, as shown in Fig. 11b, the exposed CNF is crushed and partially exposed to the pit. The top diameter of the CNF is significantly smaller than that of the middle. It was believed that a carbon film was formed from the debris of the CNFs. Thus, the typical CNFs were hardly observed, whereas a large number of carbon elements were detected by EDS as we mentioned before (Fig. 7). 


\section{Conclusions}

1. The UTS and YS of the $0.9 \mathrm{wt} \% \mathrm{CNFs} / \mathrm{A} 356$ nanocomposite fabricated via ultrasonic stirring were 21.9 and $38.3 \%$ higher than those of the matrix alloy, respectively. Meanwhile, microhardness of the composite was $106 \mathrm{HV}$ at CNFs content of $1.2 \mathrm{wt} \%$, which was an increase in $47 \%$ enhancement as compared with matrix.

2. The addition of CNFs resulted in a significant increase in the abrasion resistance and a decrease in the friction coefficient. At $40 \mathrm{~N}$, the samples of CNFs/A356 nanocomposites exhibited better stability of the coefficient of friction during wear tests. The results exhibited that the coefficient of friction of nanocomposite and wear rate were effectively reduced to 0.359 and $13 \times 10^{-3} \mathrm{~mm}^{3} / \mathrm{m}$ by incorporation with $1.2 \mathrm{wt} \%$ of CNFs, which were 26 and $39 \%$ lower than those of the matrix alloy. Also under different applied loads, $1.2 \mathrm{wt} \% \mathrm{CNFs} / \mathrm{A} 356$ composites were tested. With increasing the applied load, the coefficient of friction decreased and the wear rate increased.

3. CNFs content is the main factor affecting the wear behavior of composites. The results of SEM and EDS showed that the CNFs were easily peeled off from the matrix during the process of wear tests and the carbon was pulverized or worn to form a carbon film serving as a solid lubricant, and consequently reduced the wear rate and the coefficient of friction. Meanwhile, the exposed CNFs attached to the matrix reduced the surface fraction of the worn surfaces, thereby reducing the wear rate and the coefficient of friction.

Acknowledgements This research is supported by the National Natural Science Foundation of China (No. 51364035) and the Natural Science Foundation of Jiangxi Province (No. 20171BAB206034).

\section{References}

[1] M.S. Silva, C. Barbosa, O. Acselrad, L.C. Pereira, J. Mater. Eng. Perform. 13(2), 129 (2004)
[2] R.G. Guan, T. Di, Acta Metall. Sin. (Engl. Lett.) 30(5), 409 (2017)

[3] D. Zhou, F. Qiu, H. Wang, Q. Jiang, Acta Metall. Sin. (Engl. Lett.) 27(5), 798 (2014)

[4] T. Miyajima, Y.I. Wai, Wear 255(1), 606 (2003)

[5] R.C. Shivamurthy, M.K. Surappa, Wear 271(9), 1946 (2011)

[6] A.M. Al-Qutub, I.M. Allam, T.W. Qureshi, J. Mater. Process. Technol. 172(3), 327 (2006)

[7] D. Mandal, B.K. Dutta, S.C. Panigrahi, Wear 265(5), 930 (2008)

[8] F.S. Rashed, T.S. Mahmoud, Tribol. Int. 42(5), 642 (2009)

[9] F. Tang, X. Wu, S. Ge, J. Ye, H. Zhu, Wear 264(7), 555 (2008)

[10] K.M. Shorowordi, A.S.M.A. Haseeb, J.P. Celis, Wear 256(11), 1176 (2004)

[11] G. Fan, Z. Yu, Z. Tan, Z. Li, D. Zhang, Acta Metall. Sin. (Engl. Lett.) 27(5), 839 (2014)

[12] A.M. Al-Qutub, A. Khalil, N. Saheb, A.S. Hakeem, Wear 297(1-2), 752 (2013)

[13] S. Zhou, X. Zhang, Z. Ding, C. Min, G. Xu, W. Zhu, Compos. Part A Appl. Sci. Manuf. 38(2), 301 (2008)

[14] I.Y. Kim, J.H. Lee, G.S. Lee, S.H. Baika, Y.J. Kimb, Y.Z. Leea, Wear 267(1-4), 593 (2009)

[15] X.H. Chen, H. Yan, J. Mater. Res. 30(14), 2197 (2015)

[16] C. Sautera, M.A. Emin, H.P. Schuchmann, S. Tavman, Ultrason. Sonochem. 15(5), 517 (2008)

[17] H. Yan, H.X. Qiu, J. Mater. Res. 31(15), 2276 (2016)

[18] C.N. He, C. Feng, J.C. Lin, E.Z. Liu, C.S. Shi, J.J. Li, N.Q. Zhao, Acta Metall. Sin. (Engl. Lett.) 29(2), 188 (2016)

[19] H. Yan, Z.X. Huang, H.X. Qiu, Metall. Mater. Trans. A 48(2), 910 (2017)

[20] C.D. Li, X.J. Wang, W.Q. Liu, K. Wu, H.L. Shi, C. Ding, X.S. Hu, M.Y. Zheng, Mater. Sci. Eng., A 597(8), 264 (2014)

[21] H. Yan, Z.W. Wang, J. Rare Earth 34(3), 308 (2016)

[22] H. Kwon, G.G. Lee, S.G. Kim, B.W. Lee, W.C. Seo, L. Marc, Mater. Sci. Eng., A 632, 72 (2015)

[23] A. Mazahery, M.O. Shabani, Trans. Nonferrous Met. Soc. China 23(7), 1905 (2013)

[24] C.C. Chen, G. Chen, H.G. Yan, B. Su, Chin. J. Nonferrous Metal. 21(6), 1258 (2011)

[25] P.K. Rohargl, R.Q. Guo, P. Huang, S. Ray, Metall. Mater. Trans. A 28(1), 245 (1997)

[26] D. Cree, M. Pugh, Wear 272(1), 88 (2011)

[27] H.J. Choi, S.M. Lee, D.H. Bae, Wear 270(1), 12 (2010)

[28] I. Kim, J. Lee, G. Lee, S. Baik, Y. Kim, Y. Lee, Wear 267(1), 593 (2009)

[29] M.M.H. Bastwros, A.M.K. Esawi, A. Wifi, Wear 307(1), 164 (2013) 